\title{
Physician-assisted dying
}

\author{
Gilbert Berdine MD
}

It is self-evident that each individual owns his or her own life. The decision to end a human life, therefore, rests with each individual. Let us leave aside decisions by individuals who are minors, or who are mentally incompetent to make such a decision. The following discussion will be only about adults who are capable of making a decision to end their own lives.

A right to end one's own life does not grant a right to assistance to end one's own life. The right to end one's own life is a negative right granting each individual freedom from interference by others while acting to end one's own life. There is no positive right to assistance from others to achieve the same end. In order to acquire assistance to end one's own life, therefore, one must enter a voluntary agreement with another person to obtain that assistance. Herein lies one set of problems with physician-assisted dying-a price (monetary or otherwise) must be paid.

Communities exist to provide individuals with security and economic advantages they would not be able to obtain without cooperation with others. Communities set standards about who is allowed to live under the protection of the community. One could live apart from a community without having to adopt the community standards, but one does not have a right to the benefits of the community without adopting those standards. Herein lies the other set of problems with physicianassisted dying—benefits require compromise.

If a helper-physician or otherwise-assists an individual in ending that individual's life, it depends on how the assistance is given. If a gunsmith sells a gun to a customer who uses the gun to kill him- or herself, that is a much different situation than if a patient hires someone to shoot the patient in the head. There is no question when the patient pulls the trigger that the patient intended to die. There can be many questions

Corresponding author: Gilbert Berdine

Contact Information: Gilbert.berdine@ttuhsc.edu DOI: 10.12746/swrccc.v7i30.571 in the second situation with a hired executioner. Once the patient is dead, the community can no longer determine the intent of the patient. Documents can be forged or coerced. There should be no surprise, therefore, that communities are more likely to permit passive assistance to ending one's own life than to permit executions of patients wanting to die. For those who object to the word execution, that is precisely what is taking place, so we should not pretend otherwise. A well-intended execution is still an execution.

Physicians are part of a community including their patients. Physicians are also part of a community of physicians. If some physicians wish to assist patients in dying-by prescribing medications for the purpose of death-these physicians should have the right to practice well-intended executions, but these physicians do not have the right to continued acceptance by the community of physicians who may object to their execution activities. It is quite possible that physicianassisted dying may lead to a schism among those who call themselves physicians with those who do not approve of physician-assisted dying requiring those who do approve to call themselves by another name.

A recent editorial in the New England Journal of Medicine illustrates this problem of acceptance of physician-assisted death by other physicians. ${ }^{1}$ The editorial challenges the practice of physicians-assisting state sponsored executions of criminals, but the arguments are equally applicable to the issue of physicianassisted dying-just because we can do something does not imply that we should do something.

From: Department of Internal Medicine, Texas Tech University Health Sciences Center, Lubbock, Texas Submitted: 5/20/2019

\section{REFERENCE}

1. Denno DW. Physician Participation in Lethal Injection. N Engl J Med 2019;380:1790-1791. 